\title{
Jahrestagung 1995
}

Die Vereinigung richtete ihre Jahrestagung 1995 vom 4. bis 7. Oktober in Wien aus. Sie war damit - nach den Jahren 1928 und 1958 - zum dritten Mal in der österreichischen Bundeshauptstadt. Der hohen Attraktivität des Tagungsortes entsprach die große Zahl der Teilnehmer. Etwa 420 - einschließlich Begleitpersonen und Gästen - waren nach Wien gekommen. Umso mehr ist hervorzuheben: Die Verantwortlichen vor Ort haben eine hervorragende Organisation geleistet, einen reibungslosen Ablauf der offiziellen Tagung gewährleistet und ein großartiges Begleitprogramm zusammengestellt. Zu danken ist dafür neben dem Wiener Vorstandsmitglied, Karl Korinek, insbesondere Bernhard Raschaner, den der Vorstand für die Tagung kooperiert hatte, und seiner Frau, Kitty Raschauer, sowie seinen Mitarbeiterinnen und Mitarbeitern.

Den Vorsitz führte Walter Schmitt Glaeser, die Aussprachen leiteten die Vorstandsmitglieder Hans-Peter Schneider (1. Beratungsgegenstand) und Karl Korinek (2. Beratungsgegenstand).

Die Mitgliederversammlung, die wie die Vorträge und Aussprachen im Festsaal der Akademie der Wissenschaften stattfand, gedachte der seit der letzten Tagung verstorbenen Mitglieder: Felix Ermacora, Hubert Armbruster, Ferdinand O. Kopp, Ludwig Fröbler, Wilhelm Wengler, Karl Maria Hettlage. Die Vereinigung wird ihnen ein ehrendes Andenken bewahren. - Zugleich konnte die Mitgliederversammlung eine Anzahl neuer Kollegen begrüßen und über Neuaufnahmen beschließen. Gegenwärtig zählt die Vereinigung 388 Mitglieder (Stand: Dezember 1995).

Nachdem die Tagungsteilnehmer zunächst von einem Vertreter der Stadt Wien und am Morgen des zweiten Tages vom Dekan der Rechtswissenschaftlichen Fakultät der Universität Wien, Peter Pieler, begrüßt worden waren, erfuhr die Vereinigung am Abend desselben Tages in der Hofburg die Ehre des Empfangs durch den Bundespräsidenten der Republik Österreich, Herrn Dr. Thomas Klestil. Ein kultureller Höhepunkt folgte am dritten Abend. Entsprechend dem seitens der Wiener Kollegen erklärten Motto „Was wäre ein ,Wiener Kongreß' ohne seinen Ball?" zelebrierte die Vereinigung im Palais Schwarzenberg nach allen Kunstregeln der Tradition einen „Wiener Ball“. Kaum geringeren Erlebnisreichtum bot das von den Wiener Gastgebern offerierte Begleitprogramm. Aus der Vielfalt der Veranstaltungen seien nur beispielhaft erwähnt die Busexkursionen nach Baden und Heiligenkreuz und nach Klosterneuburg, der Tee-Empfang im Palais Ferstel mit dem Burgschauspieler Karlheinz Hackl sowie die 
unterschiedlich akzentuierten Führungen durch (Alt-)Wien und seine Museen. Der Tagungsausklang am Samstag führte schließlich nach Krems (mit einem Empfang durch den örtlichen Bürgermeister) und nach dem Stift Göttweig zu einem Mittagsempfang durch den Landeshauptmann von Niederösterreich; abends nutzten zahlreiche Teilnehmer noch die Gelegenheit zu einem Besuch der Wiener Staatsoper.

Das Vorwort zum Wiener Tagungsband sei abschließend zu einem Nachwort zur Tagungsstatistik genutzt. Es beabsichtigt, Klarheit zu schaffen über die korrekte Zählweise der Tagungen der Vereinigung. Denn darüber ist in der Vergangenheit manches Mißverständnis entstanden. Vermutlich wurde dies vor allem durch die Unsicherheiten darüber verursacht, ob die Gründungstagung der Vereinigung des Jahres 1922 zugleich als erste Jahrestagung anzusehen und wie die Berliner Sondertagung vom Frühjahr 1990 in die Zählweise einzureihen sei. Nachfolgender Vorschlag beruft im wesentlichen auf der Eröffnungsansprache von Heinrich Triepel zur Jenaer Tagung 1924 (in: VVDStRL, Bd. 1), dem Bericht von Kanrad Hesse zum fünfzigjährigen Bestehen im Jahre 1972 (in: AöR, Bd. 97, S. 345 ff.) und dem Festwort von Hans Peter Ipsen zum siebzigjährigen Bestehen der Vereinigung im Jahre 1992 (VVDStRL, Bd. 52). Danach ist die Berliner Gründungstagung von 1922 als erste (Jahres-)Tagung der Vereinigung zu rechnen. Ihr folgt die Jenaer Tagung von 1924 als zweite. Mit dieser beginnt die Zählung der VVDStRL-Bände, weil die Gründungstagung keinen Niederschlag in einem Veröffentlichungsband (sondern in: AöR 43 [1922], S. $267 \mathrm{ff}$.) erfahren hat. Nachdem auch 1930 keine Tagung stattgefunden hatte, war mithin die Hallenser Tagung von 1931 die achte und die Heidelberger Tagung von 1949, die die Vereinigungspraxis der Vorkriegszeit wiederaufnahm, die neunte (Jahres-)Tagung der Vereinigung. Nach ununterbrochener Tagungsfolge im Jahresrhythmus hielt die Vereinigung somit ihre 32. (Jahres-)Tagung ab - veröffentlicht in VVDStRL, Bd. 31 -, als sie 1972 in Salzburg ihr fünfzigjähriges Bestehen feierte. Die Sondertagung von 1990, deren Verhandlungen in einem eigenen Band der VVDStRL (Bd. 49) publiziert sind, veränderte die hergebrachte Zählgewohnheit. Die reguläre Herbsttagung des gleichen Jahres wurde numerisch zur 51. Tagung der Vereinigung insgesamt, war aber die 50. Jahrestagung, veröffentlicht in VVDStRL Bd. 50. Der Bezifferung nach besteht also derzeit Übereinstimmung zwischen Jahrestagung und Tagungsband, während die Zahl sämtlicher Tagungen der Vereinigung um die eine Sondertagung erhöht ist. Dem folgend fand sich die Vereinigung im 73. Jahre ihres Bestehens in Wien zu ihrer 55. Jahrestagung (56. Tagung insgesamt) ein.

Je eine Ziffer weiter wird dementsprechend die Jahrestagung 1996 benennen, die vom 2. bis 5. Oktober in Dresden stattfinden wird (56. Jahrestagung). Für 1997 ist der Tagungsort Osnabrück, und für 1998 hat die Wiener Mitgliederversammlung mit Dank die Einladung nach Potsdam angenommen.

W.S.G. 